\title{
os grandes estancieiros e além: criadores de gado na fronteira meridional do brasil (alegrete, 1831-1970)*
}

\author{
Luís Augusto Farinatti \\ Doutor em História Social pela UFRJ. Professor Adjunto do Curso de História da UNIFRA (Santa \\ Maria-RS)
}

RESUMO

Durante muito tempo, costumou-se reduzir as regiões pecuária do extremo-sul do Brasil à dicotomia"grandes estancieiros e seus peões". Este artigo vem somar-se a trabalhos recentes, que têm buscado demonstrar a diversidade social existente naquelas regiões. São analisadas as conjunturas da produção pecuária, bem como as unidades produtivas e os atores sociais que as levavam adiante. Um pequeno grupo de grandes estancieiros convivia com uma larga base de médios e pequenos produtores. Ao lado do trabalho de peões livres, os escravos desempenhavam papel estrutural na grande pecuária. O espaço privilegiado para a análise é o município de Alegrete, localizado na Campanha Rio-grandense, a principal região pecuária do Rio Grande do Sul. As fontes utilizadas são, principalmente, uma amostra de inventários post mortem, com auxílio de fontes qualitativas.

Palavras-chave: História Agrária - Fronteira Sul do Brasil — Estrutura agrária — Estâncias - Século XIX

\section{ABSTRACT}

The ranching areas of the borderlands in south of Brazil have been described through the dichotomy: "estancieiros" and their "peões" (free workers). This article intends to demonstrate the existent social diversity in those areas. The conjunctures of the cattle production are analyzed, and also the productive units and the social actors. A small group of great "estancieiros" was above a wide base of medium and small producers Beside the free workers, the slaves played structural part in the ranching system. The privileged space for the analysis is Alegrete, located in the "Campanha Rio-grandense", the main cattle area of Rio Grande do Sul. The used sources are, mainly, a sample of testamentary acts, with aid of qualitative sources.

Keywords : Agrarian history - South border of Brazil - Agrarian structure - Ranching System

* Uma versão preliminar de parte deste trabalho foi apresentada como comunicação nas II Jornadas de História Regional Comparada, realizadas em Porto Alegre, em 2004 Outra integrou minha Tese de Doutorado, presente nas referências bibliográficas. Agradeço aos colegas e aos membros da banca pelas observações que fizeram em ambas as oportunidades. Agradeço, também, aos pareceristas anônimos da revista, por suas observações. Submetido: outubro, 2007; aceito: abril, 2008. 


\section{Introdução}

A imagem celebrizada da Fronteira Meridional do Brasil, no século XIX, descreve a região como uma área caracterizada pela presença avas $\neg$ saladora de grandes estancieiros, donos de reses, que se contavam aos milhares. Eles teriam recebido sesmarias na fronteira, tornando-se um grupo latifundiário que monopolizara a terra. Esse monopólio teria inviabilizado as possibilidades daqueles que não se tornaram estancieiros em terem acesso à produção autônoma. Esse processo teria gerado uma estrutura social extremamente simplificada: de um lado, estancieirossesmeiros e, de outro, peões, que não tinham outra opção a não ser empregarem-se por baixos salários nas grandes estâncias'.

A proposta deste artigo é colocar em questão essa visão da estrutura agrária sulina. Nesse sentido, vai ao encontro dos resultados obtidos por alguns trabalhos surgidos nos últimos $\operatorname{anos}^{2}$. Aqui, a análise será centrada na região da Campanha Rio-grandense, área de fronteira com a República do Uruguai. Aquela era a principal região pecuária da Província do Rio Grande do Sul. Para tanto, trabalhei com uma amostra de 206 inventários post mortem, abertos no município de Alegrete, o principal da Campanha, entre 1831 e 1870. Destes, 181 processos apre sentavam bens rurais e foram considerados neste estudo. Em primeiro lugar, são tratados aspectos referentes à produção pecuária e, depois, parte-se para uma análise da evolução da estrutura agrária local, ao longo do período em tela.

\footnotetext{
Essa visão predominou mesmo em obras com diferentes orientações teóricas, como: Cardoso, (1977); Freitas, (1980). Por suavez, os trabalhos pioneiros e importantes de Pesavento e Maestri apontaram que não houve total proletarização dos subalternos, mas não atribuíram esse fator à possibilidade da produção autônoma regular e sim ao acesso ao gado bravio e ao contrabando. Além disso, não percebem ou não valorizam a existência de pequenos e médios criadores de gado, nem consideram o trabalho escravo como um fator-chave e regular na produção pecuária. Pesavento (1986); Maestri (1984, 2002).

Entre outros, podemos citar Osório (1999), Zarth (2002), Garcia (2005), Farinatti (2007a).
} 


\section{Um mundo de gado: produção pecuária nos inventários post mortem}

O gado bovino era amplamente majoritário no que tange ao núme $\neg$ ro de animais criados e, de forma ainda mais marcante, no que se refe $\neg$ re ao valor desses diversos tipos de animais, como demonstram os dados da tabela 1.

Tabela 1 - Participação dos tipos de animais no rebanho total (Alegrete, 1831-1870)

\begin{tabular}{l|c|c|c|c|c|c|c|c}
\hline \multirow{2}{*}{} & \multicolumn{2}{|c|}{$1831-40$} & \multicolumn{2}{c|}{$1841-50$} & \multicolumn{2}{c|}{$1851-60$} & \multicolumn{2}{c}{$1861-70$} \\
\cline { 2 - 9 } & ANIMAIS & VALOR & ANIMAIS & VALOR & ANIMAIS & VALOR & ANIMAIS & VALOR \\
\hline Bovinos & $84,6 \%$ & $88,4 \%$ & $75,7 \%$ & $84,6 \%$ & $62,7 \%$ & $84,5 \%$ & $72,4 \%$ & $84,2 \%$ \\
\hline Eqüinos & $8,0 \%$ & $9,2 \%$ & $19,1 \%$ & $13,3 \%$ & $22,5 \%$ & $10,6 \%$ & $13,0 \%$ & $11,1 \%$ \\
\hline Ovinos & $7,3 \%$ & $1,3 \%$ & $4,5 \%$ & $0,6 \%$ & $13,4 \%$ & $2,8 \%$ & $13,0 \%$ & $3,7 \%$ \\
\hline Muares & $0,2 \%$ & $1,2 \%$ & $0,7 \%$ & $1,5 \%$ & $1,6 \%$ & $2,1 \%$ & $0,9 \%$ & $1,0 \%$ \\
\hline
\end{tabular}

Fonte: 181 inventários post mortem. Alegrete. Cartório de Órfãos e Ausentes. Cartório do Cível e Crime. Cartório da Provedoria. 1831 a 1870 . APRS.

Não resta dúvida de que a principal produção pecuária em Alegre $\neg$ te era a criação de gado vacum, dominante em todas as décadas, como parece haver sido o tom de toda a vida produtiva da Campanha, duran $\neg$ te o século XIX. Ao mesmo tempo, é bastante claro que essa especialização não era absoluta e experimentou modificações ao longo do período. Os maiores índices alcançados pelo número de bovinos em relação aos outros rebanhos encontram-se nos dados referentes à década de $1830^{3}$. É uma pena que não haja como contar com qualquer tipo de censo agrário que possa informar sobre essas proporções para os primeiros trinta anos daquele século, quando os luso-brasileiros realiza $\neg$ ram a instalação de estâncias e a apropriação oficial daqueles campos.

De qualquer forma, ao perceber que, em sua tese de doutorado, Helen Osório encontrou uma tendência ascendente da dominância de bovinos sobre os outros animais, para o período colonial, tendo como ápice o decênio de 1815 a 1825 , é possível argumentar em favor de uma

Para os efeitos deste trabalho, agrupei sob a rubrica "muares", não apenas as mulas presentes nos inventários, mas também os asininos: os burros hechores que, ao cru zarem com as éguas geram a mula, que é um animal híbrido e estéril; e as burras, termo pelo qual eram designadas as fêmeas que geravam os burros hechores. 
permanência desse padrão em Alegrete, na década de $1830^{4}$. Natural $\neg$ mente, é preciso ter em conta que Osório trabalhou com uma amostra que envolvia todo o Rio Grande de São Pedro, o que alerta para ter cautela sobre qualquer ímpeto de comparação direta com o caso estu $\neg$ dado aqui. Todavia, é também significativo o fato de que a região da Campanha somente passou a integrar aquele mesmo espaço nas décadas finais do período colonial, exatamente quando os números passam a apontar a maior presença dos bovinos. Os dados dos anos 1830, em Alegrete, estavam refletindo um rescaldo tardio do momento feliz vivi $\neg$ do pela pecuária rio-grandense nas primeiras décadas do Oitocentos. Esta época foi marcada pela incorporação de terras e animais no pro $\neg$ cesso de ocupação de uma nova fronteira. Tratava-se do processo de conquista e ocupação estável das áreas disputadas com o império Espa $\neg$ nhol, onde hoje fica localizada a metade oeste do Estado do Rio Grande do Sul e parte da República do Uruguai.

No entanto, o fulgor demonstrado pelos índices de especialização bovina na década de 1830 não se manteve duas décadas seguintes, recuperando-se somente após 1860 , sem, contudo, alcançar novamente os pa $\neg$ drões iniciais. A análise da evolução das médias de animais (vacuns, cavalares, ovinos e muares) por inventário, aliada a referências de caráter qualitativo, parece indicar que esse declínio no percentual de vacuns se deveu a uma verdadeira diminuição dos rebanhos bovinos e não apenas a uma elevação na presença de outros tipos de animais. Vejamos os dados do gráfico A.

A média de 3.833 vacuns por inventário, alcançada no primeiro período, despenca para 1.166 nos anos seguintes e, daí, para seu ponto mínimo, com 795 reses na década de 1850, voltando a subir, para alcançar os 1.291 bovinos na década seguinte, número que, todavia, não che gava à metade daquele existente nos anos 1830. Como veremos, houve uma sensível diminuição no tamanho dos estabelecimentos pecuários ao longo do período trabalhado e, provavelmente, uma correspondente ampliação de seu número, embora não haja como saber disso com cer teza. Esse processo certamente teve influência no decréscimo das médias de cabeças de gado por inventário, observadas no gráfico A. Entretanto,

\footnotetext{
A autora considerou "estancieiros" aqueles produtores que contavam com mais de 100 cabeças de gado vacum (OSÓRIO, 1999:110).
} 
para além dele, aqueles números parecem expressar uma verdadeira diminuição dos rebanhos do município, entre 1840 e meados da década seguinte, e uma recuperação daí para os anos 1860 .

Gráfico A - Número médio de reses por inventário (Alegrete, 1831-1870)

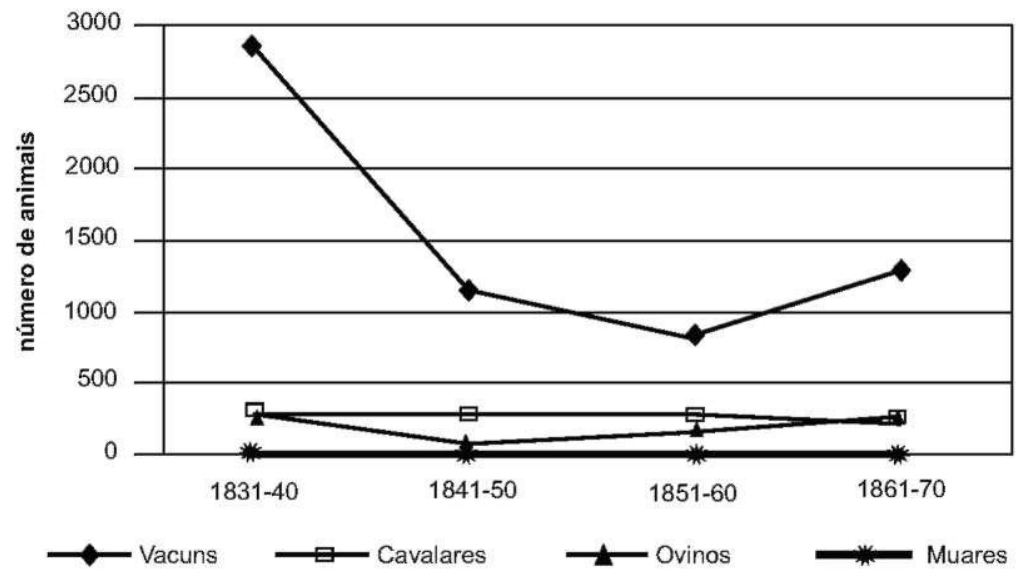

Fonte: 181 inventários post mortem.Alegrete. Cartório de Órãos e Ausentes. Cartório do Cível e Crime. Cartório da Provedoria. 1831 a 1870 .APRS.

A média de 3.833 vacuns por inventário, alcançada no primeiro período, despenca para 1.166 nos anos seguintes e, daí, para seu ponto mínimo, co m 795 reses na década de 1850, voltando a subir, para alcançar os 1.291 bovinos na década seguinte, número que, todavia, não chegava à metade daquele existente nos anos 1830. Como veremos, houve uma sensível diminuição no tamanho dos estabelecimentos pecuários ao longo do período trabalhado e, provavelmente, uma correspondente ampliação de seu número, embora não haja como saber disso com cer teza. Esse processo certamente teve influência no decréscimo das médias de cabeças de gado por inventário, observadas no gráfico A. Entretanto, para além dele, aqueles números parecem expressar uma verdadeira diminuição dos rebanhos do município, entre 1840 e meados da década seguinte, e uma recuperação daí para os anos 1860 .

De fato, o período que se iniciou em 1840 foi especialmente aziago para a produção pecuária no município. Naquele mesmo ano, a durís- 
sima combinação de uma forte seca com uma epizootia atingiu os reᄀ banhos de várias localidades, sendo especialmente mortífera em Alegrete (CÂMARA, 1863). Co mo bem apontou Berenice Corsetti, os presidentes da província derramaram queixumes sobre a situação da pecuária em todo o Rio Grande do Sul no período posterior ao final da Revolução Farroupilha. Falavam das secas, das pestes, do roubo de gado, dos efeitos tenebrosos da guerra recém-terminada (CORSETTI, 1983:84). Todos dão conta de uma "espantosa diminuição dos gados", acontecida no período, que teria prejudicado fortemente a economia da província como um todo ${ }^{5}$. Os vestígios desta crise também podem ser lidos nas petições juntadas aos processos de inventário post mortem. Em 1854, ao longo dos procedimentos do inventário de dona Febrônia Cândida Ortiz, o genro, João Telles de Souza, ajuizou uma justificação, pedindo que as 600 reses que recebera, em 1838, não fossem avaliadas pelo preço corrente, mas pelo da época da doação. Ali, arrolava testemunhas que afirmaram que aqueles animais tinham sido trasladados ao campo da Palma em 1840 e, então, haviam perecido, em virtude das conhecidas pestes e secas ocorridas naquele ano e nos seguintes ${ }^{6}$.

Passado esse período mais letal, novos recrudescimentos voltariam ainda a emergir de tempos em tempos, pelo menos até a metade da década de 1850. Em 1859, o presidente da província encaminhou um questionário a diversos estancieiros, indagando suas opiniões sobre as causas da epizootia que, em ondas, vinha flagelando os gados da provín cia "há mais de quinze anos" e pedindo sugestões sobre os possíveis

\footnotetext{
"Relatório do Presidente da Província de São Pedro do Rio Grande do Sul, Senador e Conselheiro Manoel Antônio Galvão, na abertura da Assembléia Legislativa Pro vincial, em 5.10.1847. Porto Alegre:Typographia do Argos, 1947,p. 21 " - "Relatório do estado da Província de São Pedro do Rio Grande do Sul, Ten. Gen. Francisco José de Sousa Soares Andréa, na abertura da Assembléia Provincial no dia $1^{\circ}$ de junho de 1849,p. 10." - "Relatório do Presidente da Província do Rio Grande do Sul de São Pedro, apresentado ao Exmo. Sr. Conselheiro José Antônio Pimenta Bueno, pelo Ten. Gen. Francisco José de Sousa Soares Andréa, tendo entregado a presidência no dia 6 de março de 1850 . Rio de Janeiro: Laemmert, 1850, p. 16." - "Relatório do Presidente da Província de São Pedro do Rio Grande do Sul, João Lins Vieira Cansação de Sinimbu, na abertura da Assembléia Provincial, em 6 de outubro de 1853. Porto Alegre: Typographia do Mercantil, 1853."

"Inventários post mortem. Alegrete. Cartório de Órfãos e Ausentes: M. 08, N. 111 , A. 1853. Arquivo Público do Rio Grande do Sul (APRS)."
} 
métodos para combatê-la'. As respostas foram variadas, compreendendo tanto os rigores da estação fria c o mo os do verão, mas, sobretudo, a ação das secas, que diminuíam o alimento e o suprimento de água para o gado. Dois criadores disseram ter conseguido salvar algumas reses man sas com sangrias e purgas, procedimento que seria, porém, impossível de administrar para todo o rebanho. Em sua resposta, o Brigadeiro Olivério Ortiz sugeriu que a falta de sal na dieta do gado poderia ser um fator agravante naquela espécie de peste, já que, no Uruguai, onde ha veria mais sal nos campos e nas águas salobres, o surto não fora tão forte, tendo ocorrido o contrário no município de Cruz Alta (na região do Planalto Gaúcho), onde os campos não eram salinos, mas os estancieiros tinham por hábito administrar sal a seus animais ${ }^{8}$.

Em seu outro flanco, a produção pecuária precisou lidar com os combates da Revolução Farroupilha (1835-45). A guerra desfalcou os rebanhos em virtude das carneações e das dispersões de animais, causa $\neg$ das pela passagem dos exércitos, da dificuldade de vigilância, que tor nava mais simples a ação de bandos de ladrões de gado (boa parte deles, desertores daquela mesma guerra) e, sobretudo, da falta de gente e cava $\neg$ los para costear os animais e impedir que se evadissem. Durante o pe ríodo da guerra, vários criadores rio-grandenses levaram seus rebanhos para a República do Uruguai, o que agravou ainda mais o problema, quando, no final da década, foram impedidos de movimentar gado pela fronteira, em razão da proibição que lhes impunham as forças dos blancos uruguaios, comandadas por Manoel Oribe (GUAZZELLI, 1998).

Em 1849, Ana Tavares Leiria, viúva duas vezes e mãe de onze filhos, abriu conjuntamente o inventário de seus dois falecidos esposos. Naᄀ quela oportunidade, declarou que "com a revolução que sofreu a Pro $\neg$ víncia e pestes perdeu todos os animais que possuía, ficando reduzida a necessidades"'. Não é possível saber exatamente quantos animais a viú va Ana Tavares possuía nos anos imediatamente anteriores à crise da década de 1840, mas o testamento de seu primeiro marido, que se encontra em anexo, informa que, em 1832, o casal era dono de cerca de

\footnotetext{
"Correspondências diversas, M. 30, A. 1859. Arquivo Histórico do Rio Grande do Sul (AHRS)."

"Correspondências diversas, M. 30, A. 1859. AHRS."

"Inventários post mortem. Alegrete. Cartório de Órfãos e Ausentes: M. 07, N. 98, A. 1849. APRS."
} 
500 cabeças de gado vacum. Pela avaliação dos bens no inventário, aber to em 1849, sabe-se que, naquela data, o rebanho estava reduzido a apenas 25 reses $^{10}$.

Quase ao mesmo tempo, no rumo sul, além da linha de fronteira, a Guerra Grande, talvez ainda mais sangrenta e devastadora, assolou não apenas os uruguaios, mas teve também efeitos diretos na economia da Campanha (B ARR AN e NAHÚM, 1967:11-60). Muitos dos produtores rio-grandenses possuíam terras, gados, vínculos familiares e negócios naquelas bandas. A mortandade dos rebanhos, nos dois lados da linha de fronteira, se refletiu em uma importante diminuição do volume de charque exportado pelo Rio Grande do Sul na década de 1840. As vendas caíram continuamente, partindo de 3.264.221 arrobas, em 1845, até atingirem as 700.074 , em 1850. A recuperação viria a partir de 1851 , quando se voltou ao patamar de mais de 1.000.000 de arrobas exporta $\neg$ das por ano (CORSETTI, 1983:319).

A queda no volume de charque exportado após 1845 também era um reflexo da dificuldade que as tropas do General Oribe, que contro lavam o norte do Uruguai, estavam impondo, para que os estancieiros brasileiros lá instalados passassem seu gado para o Rio Grande do Sul. Em 1851, com o final da Guerra Grande e o tratado daí decorrente, que isentava de impostos o gado que passasse do Uruguai para o Brasil, muitos criadores brasileiros compraram ou arrendaram campos do lado uruguaio, aproveitando suas melhores pastagens, em uma época de paz e de isenção de direitos alfandegários do gado, que seria trazido de lá para as charqueadas brasileiras (SOUZA e PR ADO, 2004). Esse gado foi essencial na recuperação da produção charqueadora e na recomposição dos rebanhos dos dois lados do limite nacional.

De fato, foi somente na década de 1860 que se apresentaram os sinais de uma recuperação dos rebanhos na Campanha Rio-grandense, pro $\neg$ piciada por um arrefecimento nas calamidades naturais e pela reorgani $\neg$ zação das atividades produtivas ao longo de mais de quinze anos de paz (BELL, 1980). A ampliação da média geral de cabeças de gado por inventário, em Alegrete, de 795 para 1.291 reses, está em consonância com o fato de que foi apenas nessa década que os volumes de charque ex-

"Inventários post mortem. Alegrete. Cartório de Órfãos e Ausentes: M. 07, N. 98, A. 1849. APRS". 
portado voltaram ao patamar de mais de 3.000 arrobas, alcançado em 1845 (CORSETTI, 1983:319). Contudo, essa recuperação iria encontrar o preço dos novilhos amplamente defasado, em virtude da violenta crise que afetava as charqueadas.

O que todos esses números demonstram é a importância da vinculação dessa economia com o mercado. As estâncias estavam organizadas, preferencialmente, para produzir novilhos para as charqueadas. A gran de demanda pelo charque nas regiões açucareiras, em inícios do século XIX e, depois, também nas áreas de expansão do café, somada à apro $\neg$ priação de boas pastagens e de manadas de gado, possibilitaram uma forma bastante viável de integração da região ao mercado brasileiro" O gado, uma mercadoria que não tem altos custos de transporte, viabi lizou que o complexo porto-charqueada, do litoral da província, pudes $\neg$ se colher os frutos da produção da Campanha, com a qual não tem uma comunicação fluvial ou marítima direta. As tropas poderiam ser condu $\neg$ zidas por terra, sem a necessidade de embarcações, para tornar os custos mais baixos. Tendo em conta esses fatores e lembrando que se tratava de um sistema de criação extensiva, é possível estender para o Rio Grande do Sul o argumento de Jonathan Brown, quando diz que o processo de construção de grandes latifúndios em Buenos Aires, no século XIX, era consistente c o m a racionalidade daquele sistema agrário ( $\mathrm{R}$ R OW N, 2002). Do ponto de vista estritamente econômico, era uma forma adequada de aproveitar as oportunidades que o mercado das plantations dava à Fronteira Meridional do Império.

\section{Potros, mulas e lã de ovelha}

Atentemos, agora, para as outras criações de animais que eram pra $\neg$ ticadas nos estabelecimentos pecuários de Alegrete, expressas no gráfico B. Ele aponta o percentual de inventários da amostra pesquisada, onde consta a presença de cada tipo de animal:

Para uma visão de conjunto sobre a integração mercantil desta e de outras regiões às plantations do sudeste, ver Fragoso (1998:117-147). 


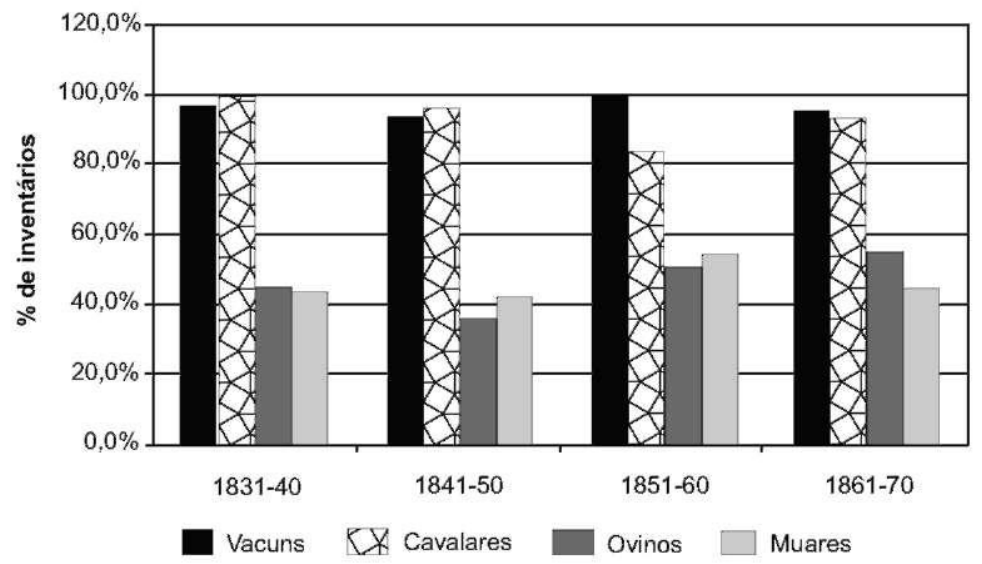

Fonte: 181 inventários post mortem.Alegrete. Cartório de Órãos e Ausentes. Cartório do Cível e Crime. Cartório da Provedoria. 1831 a 1870 .APRS.

Os gados vacum e cavalar foram relacionados em quase todos os inventários, ao longo do período estudado. As exceções ficam por par te de uns poucos produtores, muito modestos. Já a presença dos muares e dos ovinos oscilou entre os 40 e os $60 \%$ dos inventários da amostra. Elas parecem claramente ter sido criações auxiliares, que podiam ganhar uma difusão um pouco maior, de acordo com as variações conjunturais, c omo foi o caso da produção de muares, na década de 1850 , e de ovinos, no decênio seguinte. Vejamos agora cada um desses rebanhos, com um pouco mais de detalhe.

A presença de cavalares acompanha a de bovinos em quase todos os inventários pesquisados, o que já era de se esperar, em se conside $\neg$ rando a necessidade de "cavalos de serviço" para o costeio do gado. Por outro lado, também havia a criação comercial de eqüinos. Na verdade, essa era mais uma interface da guerra e da economia naque $\neg$ las campanhas. Os espólios de guerra abasteciam as estâncias com animais em toda a primeira metade do Oitocentos, ainda que isso tenha tido um peso mais decisivo nas primeiras décadas daquele sé culo. Por outro lado, a guerra também era um mercado, sobretudo para os cavalos criados naquelas unidades produtivas. A demanda de cavalos 
era enorme nas guerras do sul, em cujos combates as cargas de cava laria exerciam papel extremamente relevante. Os rebanhos de animais cavalares parecem ter resistido melhor à guerra, nas estâncias. O gráfico B mostra que os cavalares tinham presença estável entre os inventários das décadas de 1830 e 1840 . E, mais, o gráfico A demonstra que, ao contrário do que ocorreu com vacuns e bovinos, a média dos cavalares por inventário não caiu, entre essas duas décadas. Sem negar a importância dos confiscos e dos roubos de cavalos, feitos pelas forças em luta, parece que parte dos criadores conseguiu manter seus rebanhos eqüinos em patamares estáveis.

Os muares e os ovinos, por sua vez, foram arrolados em cerca de metade dos inventários da amostra. Os muares eram criados com finalidade quase que exclusivamente comercial. Desde os tempos coloniais, tropeiros desciam de São Paulo, dos Campos Gerais do Paraná, de Lages, e voltavam com tropas de muares, consistindo em uma das mais impor $\neg$ tantes atividades econômicas do período (HAMEISTER, 2005). No meado do século XIX, o principal destino dos muares produzidos no Rio Grande do Sul seguia sendo a Feira de Sorocaba, de onde eram encaminhados, principalmente para as regiões cafeicultoras do Rio de Janeiro e, depois, de São Paulo. O negócio de formação de tropas, com postas, sobretudo, por muares — ainda que possuíssem também alguma participação de eqüinos, sua invernagem nos campos do Paraná e sua venda na Feira de Sorocaba - construiu algumas fortunas de grande importância no Oitocentos, sobretudo na Província de São Paulo e na comarca, depois Província do Paraná (PETRONE, 1976; WESPHALEN, 1995). No Rio Grande do Sul, ainda que a principal produção de muares se fizesse no norte da província, nos municípios de Cruz Alta e Passo Fundo, a Campanha não estava fora desse circuito, como fica claro no gráfico B. Em Alegrete, os muares, que, nos períodos anteriores, estiveram presentes em 40 a $45 \%$ dos inventários, ampliaram um pouco sua presença para $55 \%$ na década de 1850 e voltaram aos padrões anteᄀ riores no decênio seguinte. Essa pequena ampliação na difusão da cria $\neg$ ção de mulas e seu retrocesso posterior se deveram a uma conjuntura favorável no mercado sorocabano e à crise que lhe sucedeu. O número de mulas comercializadas na feira de Sorocaba ascendeu continuamen $\neg$ te, ao longo da primeira metade do século XIX, tendo dado um salto na década de 1850 , retrocedendo a partir da década de 1860 , até entrar 
em profunda crise, quando da difusão das ferrovias, no final do século (WESTPHALEN, 1995, ZARTH, 1987).

A produção de mulas implicava na posse de uma manada de ventres cavalares (o que era de acesso relativamente comum aos produtores de Alegrete), em uma demanda específica de trabalho e na presença dos "burros hechores", os reprodutores asininos que, cruzados com as éguas, geram a mula, um animal híbrido e estéril. Os primeiros tempos de vida também exigiam um cuidado maior, dada a fragilidade das crias. A pos $\neg$ se das éguas e dos "burros hechores" permitia que se praticasse essa cria $\neg$ ção, mas isso podia não ocorrer todos os anos, variando de acordo com as avaliações que o produtor fazia em relação à viabilidade das vendas, à disponibilidade de pastagem e à mão-de-obra.

Os ovinos, por sua vez, serviam para o abastecimento interno de carne nas estâncias. Apenas pequenos excedentes de lã eram encaminha dos ao mercado local. Essa situação começou a mudar a partir da década de 1850 e, sobretudo, da de 1860, quando a província passou a exportar lã com regularidade (SILVA, 1979). Em Alegrete, os ovinos também so? freram muito com a guerra, as secas e as epizootias da década de 1840. A média de animais por inventário, que era de 245 na década de 1830 , despencou para apenas 70 nos dez anos seguintes, voltando a subir para 166 nos anos 1850 e chegando a 243 na década de 1860. Assim, na dé cada em que apareceram os primeiros registros de exportação de lã pela província, dotados de regularidade, o número de ovinos por inventário voltou a alcançar a média da década de 1830.

Naquele novo contexto, porém, esses animais estavam mais bem distribuídos, como atestam os dados do gráfico B, onde se pode notar uma ampliação na difusão da criação de ovinos no município, ao longo do período. Na década de 1840 , apenas $36 \%$ dos inventários registravam a presença daqueles animais. No decênio seguinte, esse número subiu para 51\%, atingindo, finalmente, 55\% dos inventários da década de 1860. Nessa década, ainda que fosse praticada em unidades produtivas de todas as envergaduras, a recuperação da criação ovina desempenhou um papel mais relevante entre os pequenos criadores, que contavam com até 500 cabeças de gado vacum e tiveram nos ovinos um importante incremen $\neg$ to produtivo. Uma parte dos pequenos criadores estava aproveitando a ampliação no mercado de lã e isso tem muito sentido. Um rebanho de até 500 reses poderia ser costeado com um trabalhador regular, o que 
permitia que os outros membros da família pudessem pastorear os re banhos de ovinos que iam criando. Além disso, podia-se criar o dobro do número de ovinos em relação aos vacuns, dentro do mesmo espaço, ou seja, essa era uma criação que se adequava à nova conjuntura de diminuição geral no tamanho das propriedades.

Entretanto, essa ampliação da produção ovina teve proporções moᄀ destas, se comparada com o processo ocorrido a partir dos anos 1850 na Argentina e 1860 no Uruguai. Os $3.677 .990 \$ 019$ arrecadados c o m a ex 7 portação de lã durante a década de 1860 atingiam apenas cerca de $7 \%$ do valor das exportações de charque, feitas pela província no mesmo período (Ibidem). Como apontou Stephen Bell, apesar de algumas iniciativas, tanto do governo provincial como de uns poucos entusiastas, no sentido da melhoria das raças destinadas à produção de lã, a ativida $\neg$ de mais especializada permaneceu marginal entre 1850 e 1870 (BELL, 1998). Não houve, no Rio Grande do Sul, nada comparável àfebre del lanar, ocorrida nos países vizinhos, que potencializou o processo de modernização pecuária naquelas regiões. Um incremento realmente significativo da produção ovina, na província, somente se daria a partir da última década do século X IX .

Como se pode perceber, havia uma predominância da produção bovina, mas não um exclusivismo. Por outro lado, é preciso notar que essa preponderância e a existência de grandes estabelecimentos pecuá rios não autorizam, porém, a reduzir a sociedade local à velha dicotomia "estancieiros x peões". A imagem que emerge do estudo das unidades produtivas, no mesmo conjunto de inventários post mortem, é bem mais diversificada.

\section{Para além dos grandes estancieiros}

A análise dos inventários post mortem demonstra que a estrutura agrária na Campanha era um tanto mais complexa do que se costuma admitir. O fato de que a produção de novilhos bovinos para as charqueadas era a principal produção daquela economia agrária autoriza a tomá-la para um estudo da concentração da atividade pecuária'².

Os dados aqui apresentados referem-se aos produtores e não às unidades produtivas. Assim, nos casos dos que possuíam mais de um estabelecimento rural, o gado destes 
Tabela 2 - Distribuição do rebanho bovino entre os produtores (Alegrete, 1831-1870)

\begin{tabular}{|c|c|c|c|c|c|c|}
\hline DIMENSÃO DO REBANHO & INVENTÁRIOS & $\%$ & & RESES & $\%$ & \\
\hline+ de 10.000 reses & 5 & 2,8 & \multirow{3}{*}{$17,7 \%$} & 86.308 & 23,3 & \multirow{3}{*}{$53,3 \%$} \\
\hline 5.000 a 10.000 & 8 & 4,4 & & 48.255 & 13 & \\
\hline 2.001 a 5.000 & 19 & 10,5 & & 62.832 & 17 & \\
\hline 1.001 a 2.000 & 21 & 11,6 & \multirow{2}{*}{$25,4 \%$} & 82.878 & 22,7 & \multirow{2}{*}{$33,8 \%$} \\
\hline 501 a 1.000 & 25 & 13,8 & & 41.063 & 11,1 & \\
\hline 101 a 500 & 60 & 33,1 & \multirow{2}{*}{$56,9 \%$} & 31.544 & 8,5 & \multirow{2}{*}{$12,9 \%$} \\
\hline Até 100 reses & 43 & 23,8 & & 16.007 & 4,3 & \\
\hline Total & 181 & 100 & $100 \%$ & 369.887 & 100 & $100 \%$ \\
\hline
\end{tabular}

Fonte: 181 inventários post mortem. Alegrete. Cartórios de Órfãos e Ausentes, Cível e Crime e da Provedoria. APRS.

Os dados dos inventários apontam para o fato de que havia uma marcante desigualdade econômica em Alegrete, expressa não apenas na propalada dualidade "estancieiros e peões", mas, inclusive, entre aqueles que desenvolviam a pecuária. Na tabela 2, os três primeiros estratos colocam em evidência um grupo de criadores que alcançava um vulto produtivo digno da imagem tradicional dos grandes estancieiros, pos $\neg$ suindo rebanhos que ultrapassavam as 2.000 cabeças de gado. Totalizavam cerca de $18 \%$ dos produtores da amostra e concentravam $53 \%$ do rebanho. Logo abaixo, vêm dois segmentos que poderíamos chamar de medianos criadores de gado, contando com rebanhos entre 501 e 2.000 reses. For mavam $25 \%$ dos inventariados e possuíam cerca de $34 \%$ do gado avalia $\neg$ do naqueles processos. Entre toda a amostra pesquisada, esses são os percentuais que se encontram mais próximos, o que torna razoável chamá-los de criadores de médio porte.

Seguindo para baixo na tabela, entra-se no grupo dos pequenos criadores, que não superavam as 500 cabeças de gado vacum e que, no melhor dos casos, poderiam dispor de cerca de 50 novilhos por ano, se não quisessem ver reduzida ainda mais a dimensão de seus rebanhos (GARAVAGLIA, 1993 e 1999; GELMAN, 1998, OSÓRIO, 1999). Formaר vam $57 \%$ dos criadores da amostra, mas não chegavam a possuir $13 \%$ do rebanho. Dentro desse estrato, localizava-se o subgrupo dos que tinham

foi somado, para se alcançar o total possuído pelo inventariado, no momento da avaliação de seus bens. 
menos de 100 reses. Em seu trabalho sobre o período colonial, Helen Osório verificou que as fontes coevas nem mesmo utilizavam o termo "criador" para designar qualquer dono de um rebanho daquelas dimensões (OSÓRIO, 1999). Isso sugere que eles deveriam, forçosamente, desempenhar também outra atividade econômica além da pecuária, para complementar suas rendas. É o mesmo que apontou Juan Carlos Garavaglia, quando analisou um grupo agrário semelhante, na Fronteira de Buenos Aires, no final do período colonial (GARAVAGLIA, 1999). Em Alegrete, eram cerca de $24 \%$ dos inventariados e possuíam algo em torno de $4 \%$ do rebanho.

A criação em pequena escala apresentava uma lógica econômica diversa da grande pecuária. Aqueles que criavam até 500 reses poderiam, em tese, manter a produção pecuária com apenas um ou, no máximo, dois trabalhadores regulares, precisando do concurso de mão-de-obra eventual apenas nos períodos da marcação e da castração, ou seja, era possível reproduzir a pecuária nesses níveis com trabalho familiar ou com o concurso de apenas mais um trabalhador, fosse ele um escravo campeiro ou um peão livre. Isso reduzia em muito os custos anuais de operação desses estabelecimentos e submetia suas condições de reproᄀ dução e sua viabilidade a critérios diversos daqueles que eram válidos para as grandes estâncias ${ }^{13}$. Aliás, uma parte dos sujeitos que procuravam trabalho regular ou eventual como peões nas grandes estâncias estavam inseridos nessas famílias (GARCIA, 2005; FARINATTI, 2007a).

Enfim, o mundo que emerge da análise dos inventários é um tanto mais complexo do que a imagem consagrada. Não há como negar que a expansão pecuária, desencadeada nas primeiras décadas do século XIX, c om a conquista e a ocupação estável da Fronteira pelos luso-brasileiros, criou um universo agrário onde havia pecuaristas de enorme vulto. No período seguinte, entre 1831 e 1870 , os grandes estancieiros marcavam presença de forma decisiva em Alegrete. Em seu trabalho sobre o Rio Grande de São Pedro, entre 1765 e 1825, Helen Osório apontou que $10,3 \%$ dos inventariados de sua amostra possuíam rebanhos superiores

\footnotetext{
Essa é também uma observação feita por Jorge Gelman em seu estudo sobre os estabelecimentos de criação na Banda Oriental, em fins do período colonial (GELMAN, 1998). Em um artigo recente, apontei a centralidade do trabalho familiar para os criadores com menos de 500 reses nos municípios de São Borja e Santa Maria, na mesma Província do Rio Grande do Sul, na década de 1850 (FARINATti, 2003).
} 
a 1.000 reses. No caso estudado aqui, esse percentual, que agruparia os grandes criadores e a camada superior do que chamei de criadores de porte médio, é de $29,3 \%$, ou seja, está multiplicado por três, em relação aos números encontrados por Osório. Isso permite caracterizar Alegre te como uma zona dominada pela pecuária em grande escala. Logo, para entender a lógica dessa atividade produtiva, dentro dos marcos crono lógicos propostos, é importante estudar esses senhores de terras, de gado e de homens, que dominavam aquele universo rural.

No entanto, eles não estavam sozinhos. Pelo contrário: nada menos do que $82 \%$ dos inventariados eram medianos e pequenos criadores. Indo além: $57 \%$ dos inventariados criavam de 500 reses para menos. Mesmo que concentrassem uma parcela minoritária do rebanho, eram socialmente muito representativos. $\mathrm{Nem}$ seria preciso lembrar que os inventários post mortem são uma fonte que tende a sobre-representar as camadas mais favorecidas da sociedade (FRA GOSO e PITZER, 1988:37), ou seja, entre os limites do quadro traçado acima está o de que, prova $\neg$ velmente, os pequenos produtores estivessem presentes de forma ainda mais importante naquele universo.

\section{0 passar dos anos}

Se tomarmos os números da concentração de reses e os desdobrar mos no tempo, aparecem variações significativas, que indicam transfor mações importantes na estrutura agrária de Alegrete, ao longo do período estudado.

O primeiro fato notável é a expressiva diminuição do percentual de grandes produtores, ao longo do tempo. Os que possuíam mais de 2.000 reses atingiam impressionantes $38 \%$, entre 1831 e 1840. Representavam, nas décadas seguintes, respectivamente, 12, 9 e 15\%. Enquanto isso, os que tinham até 500 reses fizeram o caminho inverso: partiram de cerca de $35 \%$ na década de 1830 , passando para $53 \%$ na seguinte e daí para $61 \%$ no terceiro período, até atingirem algo em torno de $72 \%$, na década de 1860. Essa transformação era radicalizada pelo fato de que, mesmo entre os grandes criadores (+ de 2.000 reses), a freqüência de estabelecimentos com mais de 5.000 ou 10.000 reses também diminuiu. Como de monstra a tabela 3 , eles eram quase $20 \%$ na primeira década tratada, mas, a partir de 1840,jamais atingirão mais do que $7 \%$ 
Gráfico C - Concentração dos rebanhos (Alegrete, 1831-1870)

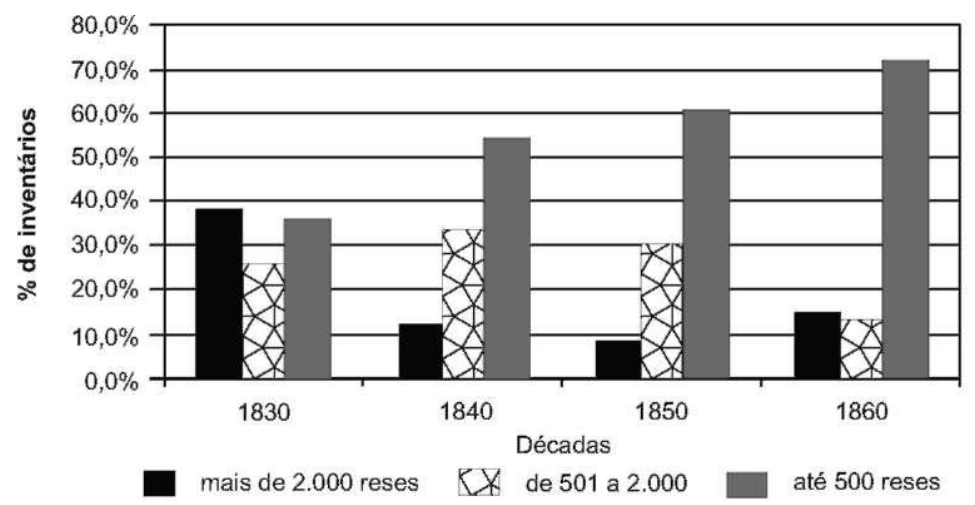

Fonte: 181 inventários post mortem. Alegrete. Cartório de Órfãos e Ausentes. Cartório do Cível e Crime. Cartório da Provedoria. 1831 a 1870 . APRS.

Tabela 3 - Criadores de gado com mais de 5.000 reses (Alegrete, 1831-1860)

\begin{tabular}{l|c|c|c|c|c|c|c|c}
\hline & $\begin{array}{c}1830 \\
\text { Inv. } *\end{array}$ & $\begin{array}{c}1830 \\
\%\end{array}$ & $\begin{array}{c}1840 \\
\text { Inv. }\end{array}$ & $\begin{array}{c}1840 \\
\%\end{array}$ & $\begin{array}{c}1850 \\
\text { Inv. }\end{array}$ & $\begin{array}{c}1850 \\
\%\end{array}$ & $\begin{array}{c}1860 \\
\text { Inv. }\end{array}$ & $\begin{array}{c}1860 \\
\%\end{array}$ \\
\hline mais de 10.000 & 3 & 7,1 & 1 & 3 & 0 & 0 & 1 & 2,1 \\
\hline de 5.001 a 10.000 & 5 & 11,9 & 0 & 0 & 1 & 1,7 & 2 & 4,3 \\
\hline Total acima de 5.000 reses & 8 & 19 & 1 & 3 & 1 & 1,7 & 3 & 6,4 \\
\hline
\end{tabular}

Fonte: 181 inventários post mortem. Alegrete. Cartório de Órfãos e Ausentes. Cartório do Cível e Crime. Cartório da Provedoria. 1831 a 1870. APRS.

* Inv. = inventários

Um dos aspectos que influiu nessa dificuldade de reprodução de estabelecimentos pecuários de enorme envergadura foi a crise conjun $\neg$ tural sofrida pela pecuária na Fronteira, na década de 1840. Como vimos, a alta média de reses por inventário, que era de 2.833 animais vacuns na década de 1830, despencou nos decênios seguintes, sem conseguir jamais retornar àqueles patamares. Esses fatores ajudam a explicar o incremento dos medianos criadores na década de 1840 , estrato inchado por uma parcela dos grandes criadores, que viram seus rebanhos se reduzirem de maneira importante, sob as dificuldades impostas pela nefasta conjunção de guerras, epizootias e secas que abalou a economia da região e fez sentir sua influência até os primeiros anos da década de 1850. Na década de 1860 , houve um "ressurgimento" dos patrimônios pecuários com 
mais de 5.000 reses. Isso indica que os rebanhos se estavam recuperando da crise conjuntural do período anterior, em razão de fatores como a maior facilidade de trânsito de gado entre os dois lados da fronteira nacional com o Uruguai, ocorrida em virtude do tratado de 1851 , e do arrefecimento de pestes e guerras, de meados da década de 1850 até meados da década seguinte.

Da mesma forma que ocorreu com o número geral de reses, aqui também essa leve alta não implicou, nem de longe, em um retorno aos percentuais da década de 1830. Parece claro, então, que esse movimento geral da configuração agrária em Alegrete não era devido apenas a fatores conjunturais, mas recebia também influências mais profundas. As crescentes dificuldades para reproduzir a pecuária extensiva (caracteri $\neg$ zada pela ausência de um incremento tecnológico importante) de grande envergadura foram fortemente condicionadas pela baixa oferta de terras, ocasionada pelo fechamento da fronteira agrária na região e, em menor escala, pelo encarecimento da mão-de-obra escrava. De fato, novos matizes aparecem, quando contrastamos esses dados com as va riações no acesso à propriedade da terra, no mesmo período.

Tabela 4 - Produtores com Terras (Alegrete, 1831-1870)

\begin{tabular}{|c|c|c|c|c|}
\hline REB ANHO & $1831-40$ & $1841-50$ & $1851-60$ & $1861-70$ \\
\hline Mais de 2.000 reses & $100 \%$ & $100 \%$ & $100 \%$ & $100 \%$ \\
\hline de 501 a 2.000 & $45,5 \%$ & $81,8 \%$ & $83,3 \%$ & $83,3 \%$ \\
\hline até 500 reses & $26,7 \%$ & $38,9 \%$ & $75 \%$ & $73,5 \%$ \\
\hline Total* & $59,5 \%$ & $60,6 \%$ & $79,7 \%$ & $78,7 \%$ \\
\hline
\end{tabular}

Fonte: 181 Inventários post mortem. Alegrete. Cartório de Órfãos e Ausentes. Cartório do Cível e Crime. Cartório da Provedoria. 1831 a 1870 . APRS.

* Esses são os percentuais de criadores com terras no universo total de criadores da década e não a média das médias de cada estrato.

Como se pode depreender dos dados da tabela 4, entre os titulares dos inventários trabalhados, os índices gerais de propriedade eram altos, mantendo uma média superior aos $50 \%$ ao longo do período em estu do. Todos os criadores que possuíam mais de 2.000 reses eram donos das terras, onde criavam seus rebanhos, e o percentual de proprietários tendia a baixar nos estratos inferiores daquela hierarquia. Isso aponta para uma vinculação entre a propriedade da terra e a possibilidade da criação em grande escala, naquele contexto. Por outro lado, todos os 
estratos de medianos e pequenos criadores apresentaram uma tendência ascendente nos percentuais daqueles que eram proprietários de terra.

Conjugando os dados da tabela 4 com os números representados no gráfico B, aparece uma importante diferença entre os diversos subperíodos trabalhados. Na década de 1830, a estrutura agrária de Alegrete estava fortemente marcada por grandes estancieiros, proprietários de vastas extensões de terra e de rebanhos que podiam ultrapassar as 2.000 e, às vezes, mesmo as 10.000 cabeças de gado vacum. Ao lado deles, pequenos e medianos criadores de gadojá se faziam presentes, forman $\neg$ do mais da metade do total de inventários da amostra para essa década. Entretanto, menos da metade dos criadores de porte médio (500 a 2.000 reses) eram donos das terras onde pastoreavam o seu gado. Essa propor $\neg$ ção baixa para cerca de $1 / 4$ dos que tinham menos de 500 reses. No caso dos que tinham até 100 , eram cerca de $1 / 6$.

Contudo, é preciso fazer a leitura desses dados a contrapelo. Se, por um lado, essa descrição aponta para uma forte concentração da proprie dade fundiária entre os grandes estancieiros, por outro, ela sugere que havia possibilidades bastante razoáveis para que os que não eram pro $\neg$ prietários de terra pudessem desenvolver a produção autônoma em campos alheios. Esse quadro enfrentou modificações importantes ao longo do período tratado. Em primeiro lugar, a proporção geral de proprietários de terras aumentou: era de cerca de $60 \%$ nas duas primei ras décadas e passou para algo em torno de $80 \%$ nas duas últimas. Essa variação se deveu, substancialmente, às alterações ocorridas nos estratos inferiores da hierarquia dos pecuaristas locais. A presença cada vez mais significativa de pequenos produtores, evidenciada no gráfico B, foi acompanhada pelo aumento da proporção daqueles, dentre eles, que eram proprietários de terras. Comparando os dados da década de 1830 e da de 1870, Graciela Garcia observou que, neste último período, haviam diminuído as possibilidades de criar seu próprio rebanho para os que não eram proprietários de terras, em Alegrete (GARCIA, 2005). os dados da tabela 4 confirmam essa observação e apontam para o fato de que o principal influxo desse processo se deu após 1850 .

Assim, ao longo do período trabalhado, o estrato dos grandes estancieiros encolheu, mas seguiu dominando a maior parte do rebanho. Essa concentração, inclusive, cresceu: se os criadores com mais de 2.000 reses eram $38 \%$, entre 1831 e 1840 , e detinham $87 \%$ dos rebanhos, na década 
de 1860 eram apenas $15 \%$ e eram donos de $82 \%$ de todo o gado vacum presente nos inventários. Essas tendências foram acompanhadas por uma valorização vertiginosa das terras, ocorrida ao longo do século XIX. Como demonstrou Graciela Garcia, em uma comparação das décadas de 1830 e 1870 , as terras valorizaram-se muito acima de todos os outros fatores produtivos. Elas subiram quase $800 \%$ de seu valor (!) entre aque las décadas, enquanto o gado vacum e o cavalar não chegaram a ter uma valorização de $100 \%$. Ovinos e muares tiveram, mesmo, uma desvalori zação (Ibidem, p. 25).

\section{Terras cada vez mais caras}

A evolução descrita acima se refletiu na composição dos patrimônios produtivos, presentes nos inventários analisados aqui:

Gráfico D - Composição do patrimônio produtivo - Inventários post mortem (Alegrete, $1831-1870$ )

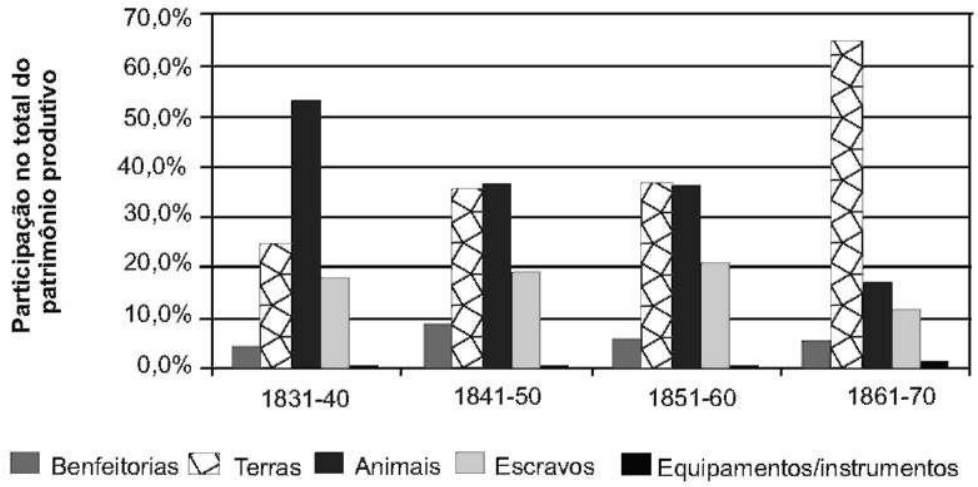

Fonte: 181 inventários post mortem. Alegrete. Cartório de Órfãos e Ausentes. Cartório do Cível e Crime. Cartório da Provedoria. 1831 a 1870 . A PRS.$^{1+}$

Foram considerados "equipamentos": carretas, carretões e carretilhas de transporte; moinhos; roda de ralar mandioca, taxo para fazer farinha, prensa com o mesmo fim, quando não estavam incluídos no valor da casa que abrigava a atafona. Foram considerados "instrumentos": laços; facas; marcas de ferro; enxadas; machados; arados; cavadeiras; pás e instrumentos de carpintaria. 
Na década de 1830, o gado ocupava uma posição majoritária, com $\neg$ pondo cerca de $53 \%$ do valor dos patrimônios produtivos. As terras e as benfeitorias rurais vinham em segundo lugar, sem conseguir chegar a $30 \%$. Nas décadas de 1840 e 1850 , os bens de raiz rurais passaram à fren te, c om 44 e $42 \%$ respectivamente, mas a situação era de relativo equilí brio, pois o gado atingiu $36 \%$ do total dos patrimônios produtivos nos mesmos períodos. Nessa época, a diminuição dos rebanhos foi compen sada por uma elevação no preço dos animais. A década de $1860 \mathrm{com} \neg$ pletou a tendência de ascensão das terras e radicalizou esse quadro. O conjunto das terras e das benfeitorias alcançou a impressionante marca de $70 \%$ do valor total dos patrimônios, enquanto o gado, cujos rebanhos cresciam, mas os preços haviam baixado muito, chegava apenas a $17 \%$ sua menor participação em todo o período estudado. O percentual ocupado pelos escravos manteve-se estável durante as décadas de 1830, 1840 e 1850 . Apenas diminuiu sua participação nos patrimônios ao lon go da última década analisada, quando tanto seu número quanto seu preço sofreram quedas. Os equipamentos e os instrumentos de trabalho, por sua vez, ficaram sempre em torno de $1 \%$, demonstrando a manu tenção de um nível tecnológico baixo, comum a todos os sistemas agrários extensivos.

O aumento do preço das terras foi, provavelmente, o resultado da combinação de diferentes fatores. Embora o presente artigo não com $\neg$ porte um estudo específico sobre esse tema, é necessário apontar pelo menos alguns dos elementos que contribuíram para esse processo. Em primeiro lugar, ele certamente sofreu influência da prática da pecuária extensiva em uma região onde as melhores terras já estavam ocupadas desde as primeiras décadas do século. Em meados do século, o fato de que as propriedades ficavam cada vez menores, implicando na redução da capacidade produtiva dos estabelecimentos pecuários, agia no sentido da valorização de cada quarto de légua de campo que pudesse ser utilizado.

Além disso, é também bastante provável que esse aumento no preço das terras tenha sofrido alguma influência do processo de aplicação da Lei de Terras no município. A Lei de Terras era de 1850 e seu regulamento datava de 1854 , mas sua aplicação obedeceu a ritmos e características diversas, nos quatro cantos do Império. Em trabalho recente, Graciela Garcia comparou a estrutura agrária de Alegrete em 
dois momentos distintos: as décadas de 1830 e 1870 (Ibidem). A partir desse procedimento, a autora identificou a diminuição dos produtores que não detinham a propriedade da terra, entre um e outro período. Isso se deveu, de um lado, ao fato de que houve o cerceamento à possibilidade de se apropriar de terras devolutas após a Lei de Terras (1850). Além disso, os proprietários foram-se tornando menos toleran tes à presença de pessoas arranchadas dentro de suas terras.

Esse parece ter sido um fenômeno geral em toda a Campanha: es ᄀ tudando uma mostra de inventários de Bagé, John Charles Chasteen também apontou a redução entre os produtores sem a propriedade da terra, ao longo do século XIX (CHASTEEN, 1991). Preocupado em mapear o contexto anterior à "Revolução Federalista" de 1893, o historiador norte-americano identificou um acirramento das tensões, tanto horizontais, entre os proprietários, como verticais, entre esses e a popu lação pobre, privada do acesso à produção independente, sobretudo a partir da década de 1870. Chasteen atribuiu essas tensões ao sistema de partilha igualitária dos bens, que reduzia continuamente as possibilida $\neg$ des de reprodução dos criadores de gado dentro do sistema da pecuária extensiva, onde era impossível manter o mesmo número de reses sem manter a mesma quantidade de terras.

Graciela Garcia vinculou essas transformações, em Alegrete, com o grande aumento do preço das terras, mas deu um passo à frente ao re lacioná-las, também, com a crise do trabalho escravo e com o processo de aplicação da Lei de Terras na região, ao longo da segunda metade do século XIX. Respeitando a complexidade do tema, Garcia mostrou que conflitos fundiários ocorreram desde o início da ocupação luso-brasileira na região, mas foram-se tornando mais incisivos e ganhando novas formas, em razão das transformações que estavam em curso na segunda metade do Oitocentos.

A autora lançou a hipótese de que o aumento significativo na proᄀ porção de pequenos criadores, entre uma e outra década estudadas por ela, significou uma ampliação na mão-de-obra livre que poderia, sazonalmente, empregar-se nos grandes estabelecimentos (GARCIA, 2005:178). Esse estrato inchado de pequenos criadores, bem como a redução das possibilidades de ser produtor "sem-terra", contribuíram para atender às necessidades das grandes estâncias, quando da crise do trabalho escravo no município. Paulo Zarth havia proposto que os la- 
vradores nacionais, expropriados das terras que ocupavam em favor da colonização, no norte do Rio Grande do Sul, serviram como trabalhadores das obras de infra-estrutura dessas mesmas colônias e também como substitutos dos escravos nas estâncias daquelas regiões (ZARTH, 1997). Garcia seguiu a mesma linha de raciocínio para afirmar que as crescentes dificuldades impostas para que se pudesse produzir sem pos $\neg$ suir a propriedade formal da terra, na Campanha, ajudaram a fornecer os substitutos para a mão-de-obra escrava na pecuária, quando esta entrou em crise (GARCIA, 2005).

No que se refere ao período estudado aqui, os dados confirmam a tendência geral das transformações, identificadas por Graciela Garcia. Através deles, podemos perceber que a década de 1850 foi um ponto de inflexão importante, pois, a partir de então, a proporção de criadores de gado sem a propriedade da terra, que havia ficado em torno de $40 \%$ nas décadas de 1830 e 1840 , decresceu e se estabilizou em torno de $20 \%$, nos dois decênios posteriores. A posse de uma parte de terras formal ou pretensamente pertencentes a outros continuava sendo empregada como estratégia pelos pequenos produtores, mas passou a encontrar mais re sistência por parte dos proprietários.

Em estudos anteriores sobre as formas de mão-de-obra empregadas na pecuária sulina a longo do Oitocentos (F A R IN A T T I, 2007b), pude perceber que as grandes estâncias mantiveram o padrão de combinar o trabalho de peões livres com o trabalho escravo (inclusive no costeio do gado), desde o início do século XIX, pelo menos o terceiro quartel daquele século.

Tabela 5 - Percentuais de criadores de gado que possuíam escravos (Alegrete, $1831 \neg$ 1870)

\begin{tabular}{|c|c|c|c|c|}
\hline & $1831-1840$ & $1841-1850$ & $1851-60$ & $1861-1870$ \\
\hline mais de 2.000 reses & $100 \%$ & $100 \%$ & $100 \%$ & $100 \%$ \\
\hline de 501 a 2.000 & $100 \%$ & $100 \%$ & $88,9 \%$ & $83,3 \%$ \\
\hline até 500 reses & $60,0 \%$ & $66,7 \%$ & $80,6 \%$ & $58,8 \%$ \\
\hline Total & $85,7 \%$ & $81,8 \%$ & $84,7 \%$ & $68,1 \%$ \\
\hline Média de escravos por inventário & 9 & 7 & 6 & 5 \\
\hline
\end{tabular}

Fonte: 181 inventários post mortem. Alegrete. Cartório de Órfãos e Ausentes. Cartório do Cível e Crime. Cartório da Provedoria. 1831 a 1870 . APRS. 
Contudo, é inegável que, após o final do tráfico atlântico de cativos (1850) e, especialmente, quando o preço do gado decaiu, após 1860, a reprodução dessa combinação de diferentes formas de trabalho começou a encontrar muita dificuldade (FARINATTI, 2007b). Essas conclusões são coerentes com o fato de que estava ficando difícil para os subalter nos terem acesso aos meios de produção, ao longo desse período. Até meados do século, muitos deles puderam reproduzir a antiga estratégia de ocupar a baixos custos um pedaço de terra, efetuar a produção agrí cola de alimentos e/ou a pecuária em pequena escala. Essa produção contava, basicamente, com mão-de-obra familiar (Idem, 2007a). Isso forçava os grandes estancieiros a lançarem mão do trabalho de escravos campeiros, porque, apesar de conseguirem contratar peões, não havia nada como um mercado de trabalho nos moldes capitalistas na região. Como haviam sugerido Zarth e Garcia, a dificuldade da reiteração das condições de produção autônoma dos setores subalternos, na segunda metade do século XIX, esteve ligada à crise da escravidão, que era, sim, um fator estrutural na produção pecuária sulina.

\section{Conclusões}

A produção agrária do município de Alegrete, na região da Cam? panha Rio-grandense, mostrou um grau importante de especialização na pecuária destinada a produzir novilhos enviados às charqueadas do leste da província. Nesse sentido, a década de 1830 apresentou as maio $\neg$ res médias de gado por inventário em Alegrete e também uma preᄀ sença mais significativa de grandes rebanhos. Fatores conjunturais, como guerras, secas e pestes, na década de 1840, trouxeram forte abalo à produção pecuária no município estudado. Esses números somente se recuperaram na década de 1860 , mas sem chegar nem perto dos valores encontrados trinta anos antes. Isso se deve ao fato de que se tratava da reprodução de uma pecuária extensiva, praticada em um contexto em que a fronteira agrária se estava fechando, sem que houvesse incre $\neg$ mento tecnológico significativo para relativizar a dependência da incorporação de novas terras. Como conseqüência, as terras tornavamse cada vez mais caras. Da mesma forma, o trabalho escravo encareceu após o final do tráfico atlântico, em 1850. Por fim, esse fator foi agra vado pelo fato de que a devastação dos rebanhos bovinos, causada pelo 
contexto bélico de meados do Oitocentos, somado ao fato de que não havia mais grandes manadas de gado bravio a incorporar (como ocor $\neg$ ria no início do século XIX).

Por outro lado, o estudo de uma amostra de inventários post mortem, secundados por fontes qualitativas, demonstrou que a estrutura agrária de um município da Campanha Rio-grandense, região de grande pe cuária, não se encaixava nas formas propostas por um renitente senso comum historiográfico. Ao invés de grandes estancieiros e seus peões, encontramos criadores de gado de diversas envergaduras econômicas. A grande concentração fundiária, de gado e de escravos, realizada por alguns poucos, não foi capaz de impedir o acesso de muitos dos menos afor tunados a alguns recursos produtivos. Eles puderam empregar uma es $\neg$ tratégia de produção autônoma, que impedia os grandes estancieiros de abdicarem do trabalho escravo como traço estrutural da produção pe cuária. Esse quadro durou, pelo menos, até meados do século XIX. Depois disso, como foi dito acima, transformações profundas entraram em curso e sua especificidade exige estudos próprios.

\section{Referências bibliográficas}

BARRÁN, José Pedro; NAHÚM, Benyamin, História Rural Del Uruguai Moderno, v. I. Montevideo: Ediciones de la Banda Oriental, 1967.

BELL, Stephen, Campanha Gaúcha: a brazilian ranching system, 1850-1928. Stanford: Stanford University Press, 1998.

B ROWN, Jonathan. Historia Socioeconómica de la Argentina, 1776-1860. Buenos Aires: Siglo XXI / Instituto Di Tella, 2002.

CÂMARA, Antônio Manoel Correa da, Ensaios Estatísticos da Província de São Pedro do Rio Grande do Sul. Revista Trimestral do Instituto Histórico e Geográfico da Província de São Pedro, v. 3, n. 2, 1869:20-28.

CARDoso, Fernando Henrique, Capitalismo e Escravidão no Brasil Meridional. $4^{\wedge}$ ed. São Paulo: Paz e Terra, 1997.

CHASTEEN, John Charles, "Background to Civil War: the process of land tenure in Brazil's southern borderland, 1801-1893". Hispanic Amercian Historical Review, 71,1991.

CORSETTI, Berenice, Estudo da charqueada escravista gaúcha no século XIX. Niterói: UFFPPGH, Dissertação de Mestrado, 1983.

FARinAtTi, Luís Augusto, "Um Campo de Possibilidades: notas sobre as formas de mão-de-obra na pecuária ( Rio Grande do Sul — século XIX)". História — Unisinos. São Leopoldo,v. 8, agosto-dezembro de 2003:253-276. 
FARINATtI, Luís Augusto, Confins Meridionais: famílias de elite e sociedade agrária na Fronteira Sul do Brasil (1825-1865). Rio de Janeiro: PPGHIS-UFRJ, Tese de Douto ᄀ rado, 2007a.

, "Trabalhadores da Pecuária: mão-de-obra livre e escrava nas estâncias da fronteira meridional do Brasil (1825-1865)". I Congresso Latinoamericano de Historia Económica. CD-ROM. Montevidéu, 2007b.

FRAGOSO,João Luiz Ribeiro; PITZER, Renato Rocha, "Barões, Homens Livres Pobres e Escravos: notas sobre uma fonte múltipla - Inventários post mortem". Arrabaldes, Niterói, $\mathrm{n}^{\circ} 2$, set./dez, 1988.

FRAGOSO, João Luiz Ribeiro, Homens de Grossa Aventura: acumulação e hierarquia na praça mercantil do Rio de Janeiro (1790-1830). Rio de Janeiro: Civilização Brasileira, 1998.

FREITAS, Décio, "O Mito da Produção sem Trabalho". In: DACANAL, J. H. e GONZAᄀ GA, S., RS: Cultura e Ideologia. Porto Alegre: Mercado Aberto, 1980.

GARAVAgLiA, Juan Carlos, "Las 'estancias' en la campana de Buenos Aires. Los medios de producción (1750-1815)". FRADKIN, Raúl O. (org.), La historia agraria del Río de la Plata colonial. Los establecimientos productivos (II). Buenos Aires: Centro Editor de América Latina, 1993.

, Pastores y Labradores de Buenos Aires: una historia agraria de la campana bonaerense (1700-1830). Buenos Aires: Ediciones de la Flor, 1999.

GARCIA, Graciela, O Domínio da Terra: conflitos e estrutura agrária na Campanha Rio-grandense Oitocentista. Porto Alegre: UfRGS-PPGH, Dissertação de Mestrado, 2005.

Gelman, Jorge, Campesinos y estancieros. Una región del Río de la Plata a fines de la época colonial. Buenos Aires: Editorial Los Libros del Rie1, 1998.

Guazzelli, César Augusto, $O$ Horizonte da Província: a República Rio-grandense e os caudilhos do Rio da Prata (1835-1845). Rio de Janeiro: UFRJ — PPGH, Tese de Dou torado, 1998.

HAMEISTER, Martha Daisson, O Continente do Rio Grande de São Pedro: os homens, suas redes de relações e suas mercadorias semoventes. $\mathrm{R}$ io de Janeiro: Universidade Federal do Rio de Janeiro, PPG - História Social, Dissertação de Mestrado, 2002.

MAESTRI, Mario, O Escravo no rio Grande do Sul. A Charqueada e a Gênese do Escravismo Gaúcho. Porto Alegre: EST, 1984. , "O cativo e a fazenda pastoril sul-riograndense". In Deus é Grande, o Mato é Maior - trabalho e resistência escrava no Rio Grande do Sul. Passo Fundo: Editora da UPF, 2002.

OSÓRIO, Helen, Estancieiros, lavradores e comerciantes na constituição da Estremadura Portu guesa na América: Rio Grande de São Pedro, 1737-1822. Niterói: Universidade Federal Fluminense, Tese de Doutorado, 1999.

PESAVENTO, Sandra, Pecuária e Indústria:formas de realização do capitalismo na sociedade gaúcha do século XIX. Porto Alegre: Movimento, 1986.

PETRONE, Maria Teresa Schroeder, O Barão do Iguape. São Paulo: Companhia Editora Nacional, 1976. 
SILVA, Elmar Manique, "Ligações externas da economia gaúcha (1736-1890)". In DACANAL, José Hildebrando; GONZAGA, Sérgius (orgs.), RS: Economia e Política. Porto Alegre: Mercado Aberto, 1979:55-92.

SOUZA, Susana Bleil e PRADO, Fabrício Pereira, "Brasileiros na fronteira uruguaia: eco $\neg$ nomia e política no século XIX". GRIJÓ, Luiz Alberto; KUHN, Fábio; GUAZZELLI, César; NEUMANN, Eduardo, Capítulos de História do Rio Grande do Sul. Porto Alegre: Editora da UFRGS, 2004:121-146.

ZARTh, Paulo Afonso, História Agrária do Planalto Gaúcho. Ijuí: Editora da UNIJUí, 1997.

Do Arcaico ao Moderno: o Rio Grande do Sul agrário do século XIX. Ijuí: Editora UNIJUÍ, 2002. 